stinal lymphadenopathy is not surprising. Paediatric series have emphasised the usefulness of bronchoscopy for the diagnosis of endobronchial disease associated with mediastinal lymph node tuberculosis. ${ }^{2}$ In adults Auregan et al reported that only three from a series of 140 patients with tuberculous mediastinal lymphadenopathy had a normal fibreoptic bronchoscopic examination and that 135 patients had one or more bronchial fistulae.

We therefore agree with Baran and colleagues that bronchoscopy is of significant diagnostic value in patients with isolated tuberculous mediastinal lymphadenopathy and may avoid more invasive procedures such as mediastinoscopy. However, rigid bronchoscopy with large sampling and/or transbronchial biopsy is probably not necessary in most patients. We believe that fibreoptic bronchoscopy with bronchial biopsy specimens should be considered as a first line examination in patients with apparently isolated tuberculous mediastinal lymphadenopathy.

O RAFFY

Service de Pneumologie, Centre Hospitalier Général de Chartres, BP407-28018 Chartres Cedex,

France

C SLEIMAN

C ROUE

Service de Pneumologie et Réanimation

Respiratoire,

Hôpital Beaujon,

92118 Clichy Cedex,

France

1 Raffy O, Cracco C, Roué C, Mangiapan G, Roux $\mathrm{F}$, Sleiman C, et al. Diagnostic value of
bronchoscopy for isolated tuberculous mediastinal lymphadenopathy (abstract). Eur Respir $\mathcal{F}$ 1995;8:386s

2 Powel DA. Tuberculous lymphadenopathy. In Schlossberg D, ed. Tuberculosis. New York: Springer Verlag, 1988:99-108.

3 Auregan G, Ali B, Chakib S, Etienne B, Migueres $\mathrm{J}$. Les adénopathies médiastinales tuberculeuses à Djibouti. Rapport de 159 cas. Rev Pneumol Clin 1990;46:216-20.

\section{Measuring systemic effects of inhaled beclomethasone}

The use of the urine cortisol/creatinine ratio for measuring the effects of inhaled beclomethasone on the hypothalamic-pituitaryadrenal axis described by McIntyre and colleagues (December 1995;50:1280-4), although less cumbersome than measuring the 24 hour urinary free cortisol excretion, nevertheless suffers from the limitation that it is an indirect assessment of plasma cortisol dependent, to a large extent, on an assumption about renal function which cannot be extrapolated to patient subgroups other than those studied by the authors. The use of the low dose adrenocorticotropin test ${ }^{1}$ not only circumvents these difficulties, but also appears to be more sensitive than the conventional short synacthen test in revealing impaired adrenal function in asthmatic subjects treated with inhaled corticosteroids. Of 46 subjects tested with 1-24 tetracosactrin in a dose of $0.5 \mu \mathrm{g} / 1.73 \mathrm{~m}^{2}, 16$ failed to reach a peak plasma cortisol level of $>500 \mathrm{nmol} / \mathrm{l}$ following a course of inhaled beclomethasone dipropionate or budesonide. These 16 patients also had a significantly lower ( $p$ $<0.001$ ) mean 24 hour urinary free cortisol excretion than patients who responded normally to this test dose. Nonetheless, 15 of these poor responders responded normally to the conventional $250 \mu \mathrm{g}$ test dose utilised in the short synacthen test.

OMP JOLOBE Tameside General Hospital, Ashton-under-Lyne, Lancashire OL6 9RW, UK

1 Broide J, Soferman R, Kivity S, et al. Low-dose adrenocorticotropin test reveals impaired adrenal function in patients taking inhaled corticosteroids. f Clin Endocrinol Metab 1995; 80:1243-6.

\section{BOOK REVIEWS}

High Resolution CT of the Chest Comprehensive Atlas. E J Stern, S J Swenson. (Pp 304; £81.50). Philadelphia: Lippincott-Raven, 1995. 0397514514

High Resolution CT of the Lung. W $\mathrm{R}$ Webb, N L Muller, D P Naidich. Second Edition. (Pp 336; £96.00). Philadelphia: Lippincott-Raven, 1995. 0781702178.

HRCT scanning has made an important contribution to the assessment of intrathoracic disease in the last 10 years. These two American books on HRCT from the same publisher approach the topic in different ways.

The atlas by Stern and Swenson is intended for "private radiology practitioners" and radiology trainees. The authors note that a disease process varies in appearance according to the individual patient and the stage of the disease. They have therefore attempted to present several examples of each condition to give a wider view than the classic presentation. There is a brief chapter on HRCT technique and another on anatomy. Unfortunately, there are no line diagrams to clarify the basic anatomy that HRCT displays. The subsequent 12 chapters deal with specific related types of conditions such as fibrotic lung disease and lung masses. Each HRCT scan has a brief description which includes some general comments on the disease process and specific remarks about the particular radiograph. The last chapter is on pitfalls and artifacts, most of which are well known to those who see a reasonable number of HRCT scans.

The book by Webb et al is the second edition of a much respected formal text which has been updated to take account of the advances of the last four years. It has a good section on the technical aspects of HRCT scanning followed by a chapter on anatomy which includes several very helpful line diagrams. There is a chapter on the radiographic findings in HRCT which is then followed by the main body of the book which is divided according to appearances - for example, parenchymal opacification or nodules. This leads to some conditions appearing in several chapters although these are generally cross referenced. It concludes with sections on the uses of HRCT and an illustrated glossary of terms. All the chapters have tables of features of particular diseases and differential diagnoses.

These books will appeal to different types of readers. Although the book by Webb et al costs $£ 15$ more, it has 30 more pages and they are full of information whilst a lot of the pages in the atlas are half empty. The images in the atlas are not quite so good. Both contain a list of references but these are much more comprehensive in the book by Webb. Anyone who wants to obtain a good understanding of the basis and use of HRCT scanning will be advised to buy the book by Webb, but those who are more interested in looking at a range of HRCT images without the support of technical and clinical detail will find the atlas useful to flick through for selection of examples. - AM

Non Invasive Respiratory Support. A K Simonds. (Pp 192; $£ 1$ 19.99). London: Chapman \& Hall, 1995. 0412568403

Nasal masks are sprouting on faces over Britain and Europe faster than teenage acne. As the arguments for use of CPAP and NIPPV rage, there are few balanced reviews of the literature to educate those new to the field until now. This knowledgeable, thorough, well argued, and extremely well laid out paperback book on assisted ventilation is now available for both newcomers and "old hands"

From the first chapter, the potted history sets the scene for the newcomer. Concise, factual, and easy to read, this is not a book to be put down in a hurry. Chapters 1 and 2 cover the background methods and pathophysiology concisely with clear tables and diagrams. Chapters 3 to 5 offer good advice on equipment and setting up patients on the different machines, but this is brief. An overview of assisted ventilation in respiratory failure (Chapter 4), followed by a series of chapters (Chapters 6 to 10 ) on specific conditions including intensive care units, domiciliary care, neuromuscular disease, chronic obstructive pulmonary disease (COPD), and pre-lung transplantation, give this book its real "value for money" feel. Chapter 9 argues the pros and cons of NIPPV in COPD very knowledgeably and fairly. Chapters 11 and 12 deal very neatly with the high problem/ small number of patients seen by only a few specialist centres. Chapter 13 addresses obstructive sleep apnoea and CPAP treatment adequately but is not extensive. The final three chapters are informative on physiotherapy, home care, and the broader picture in Europe, and underline the thoroughness of the book. The only disappointing factor is that some of the figures and illustrations are poor (especially figures $3.5,3.12,3.13$, and 10.1), and in fig 11.1 the top panel is mislabelled as $\mathrm{PaCO}_{2}$ when it should be $\mathrm{PaO}_{2}$. These are minor drawbacks and may represent cost cutting to keep the book keenly priced and thus widely available.

I suggest that any centre considering purchasing any form of non-invasive ventilation should consider buying this book before writing their business plan. For teaching material, this is a modern essential. I would recommend that all personnel involved with assisted ventilation (registrars and above, respiratory scientists and physiologists, nurses and physiotherapists) should buy or read this book soon. - BGC 